\title{
Map of Japan \\ in the Sixteenth Century
}




\section{MAP OF JAPAN}

IN THE SIXTEENTH CENTURY

7 The Tenka, Oda Nobunaga's realm, at his death in 1582

i Headquarters of major Buddhist organizations

$\mathbf{x}$ Sites of major battles

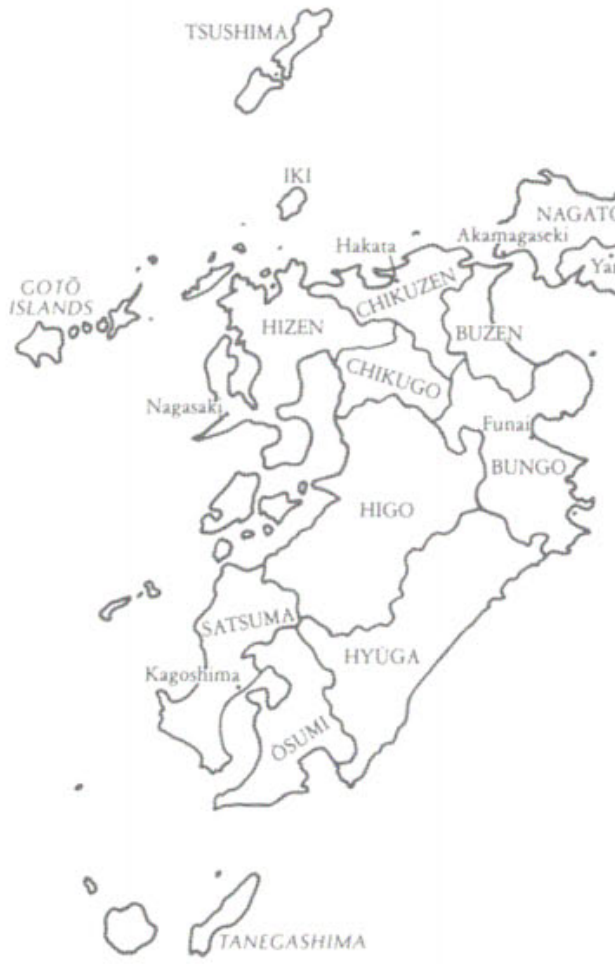

$\$ 0$ 


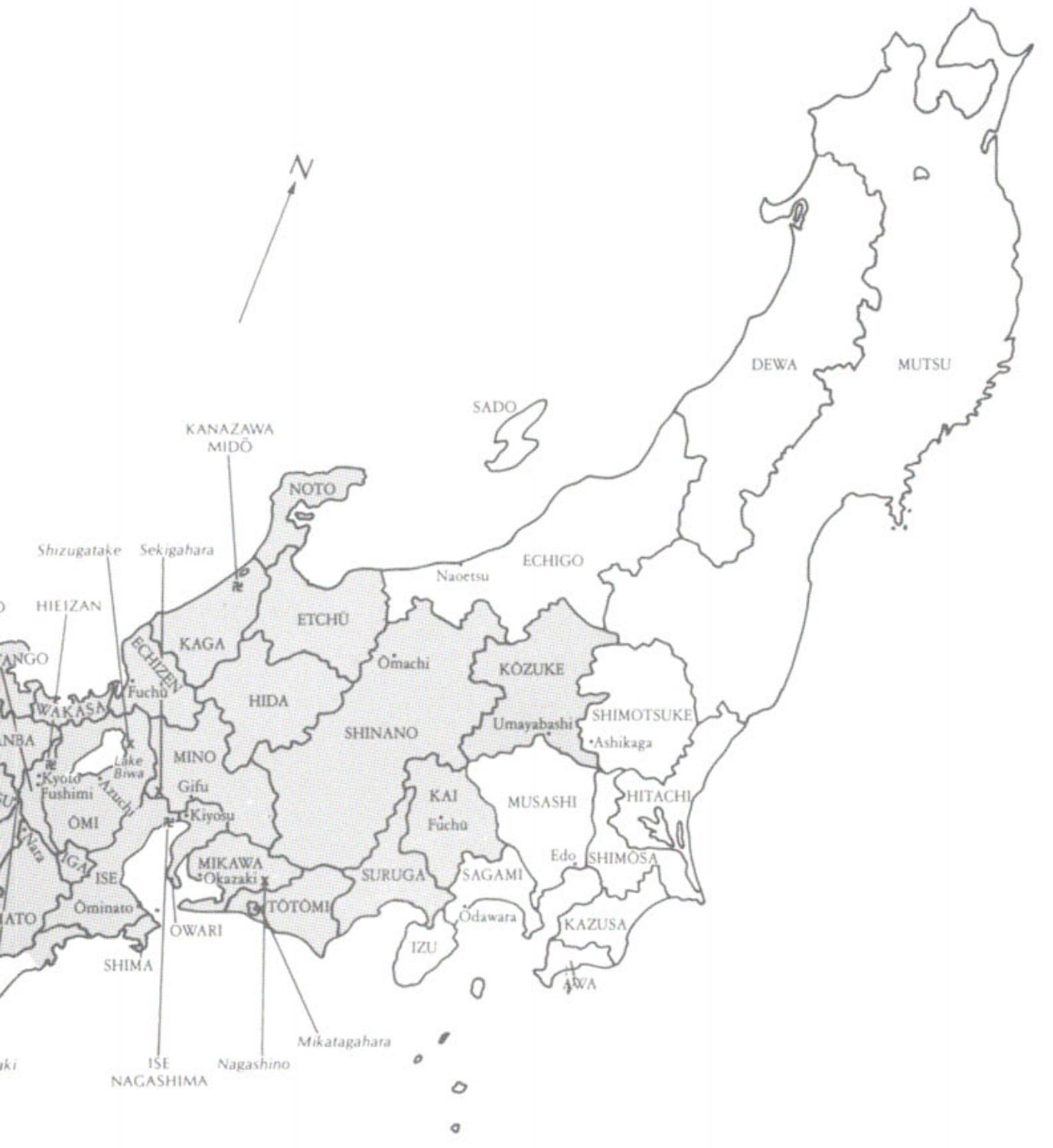



Warlords, Artists, and Commoners 
